\title{
Proposta de material didático para a história das relações étnico-raciais ${ }^{1}$ \\ Proposal for the compiling of teaching material on the history of race relations in Brazil
}

Verena Alberti*

\section{Resumo}

$\mathrm{O}$ artigo discute diretrizes e sugestões para a elaboração de materiais didáticos sobre a história das relações raciais no Brasil, considerando especialmente sua disponibilização na internet. A proposta parte de pressupostos que concernem, de um lado, ao ensino de história e, de outro, ao uso de tecnologias de informação e comunicação na elaboração de conteúdo pedagógico. São apresentados nove conjuntos de questões, com sugestões de fontes e tarefas a serem executadas pelos alunos, abarcando desde a opção pelo trabalho escravo na América Portuguesa até a polarização que se verifica atualmente entre os que defendem políticas de promoção da igualdade racial e os que são contrários a elas.

Palavras-chave: ensino de história; uso de tecnologias da informação e comunicação no ensino de história; ensino de história e cultura afro-brasileira.

\section{Abstract}

The paper discusses guidelines and suggestions for the compiling of teaching material on the history of race relations in Brazil, considering its placement on the internet. The proposal is based on some assumptions from the field of history education and of the uses of ICT in pedagogical material. It presents nine sets of enquiry questions, each of them related to a range of historical sources to be worked out by pupils through specific tasks. It embraces topics from slave labour, in the 16th century, to the polarization observed nowadays between those who defend affirmative actions and those opposing them.

Keywords: history education; ICT and history teaching; teaching of AfricanBrazilian culture and history.

\footnotetext{
*Coordenadora de Documentação - Centro de Pesquisa e Documentação de História Contemporânea do Brasil (CPDOC) - Fundação Getulio Vargas - Praia de Botafogo, 190, 14º andar. 22250-900 Rio de Janeiro - RJ - Brasil. verena.alberti@fgv.br
} 
A Lei 10.639/2003, que torna obrigatório o ensino de história da África e de história e cultura afro-brasileira, posteriormente modificada pela Lei $11.645 / 2008$, que acrescentou à obrigatoriedade o ensino da história e cultura indígenas, trouxe desafios interessantes para historiadores e professores de história, militantes de movimentos negros e indígenas, pesquisadores e educadores de modo geral. Um dos desafios, sentido especialmente nos primeiros anos após a promulgação da lei e que vai sendo vencido pouco a pouco, é a escassez de material didático sobre as relações étnico-raciais. Este texto pretende discutir diretrizes e sugestões para a elaboração de materiais sobre o assunto, considerando especialmente sua disponibilização em formato eletrônico, preferencialmente na internet.

A proposta parte de alguns pressupostos que concernem, de um lado, ao ensino de história e, de outro, ao uso de tecnologias de informação e comunicação (TIC) na elaboração de conteúdo pedagógico. Em seguida, apresenta algumas possibilidades de aplicação, com fontes e tarefas a serem executadas pelos alunos.

\section{PRINCÍPIOS NORTEADORES I: SOBRE ENSINO DE HISTÓRIA}

No que diz respeito ao campo do ensino de história, um princípio fundamental a ser observado no dossiê aqui proposto é o comprometimento com o rigor histórico. Isso pode parecer óbvio, e devia sê-lo, mas nem sempre é observado por professores e produtores de material didático em história. Seguir esse princípio significa não estar de acordo com a ideia de que qualquer afirmação possa ser feita a respeito do passado. Acuidade e clareza de reflexão são, pois, cruciais aqui.

A proposta também considera importante compreender as pessoas no passado. Como já tive oportunidade de desenvolver alhures, a ideia central, nesse caso, é ensinar aos alunos que as formas como as pessoas agiam e pensavam no passado faziam sentido de acordo com suas ideias sobre o mundo, as quais nem sempre (ou quase nunca) são as mesmas de hoje. ${ }^{2}$ Isso é fundamental porque nos ajuda a perceber similaridades e diferenças em relação ao presente e a verificar, no caso deste dossiê, que as relações raciais em diferentes momentos do passado não foram sempre iguais, nem são iguais às que se verificam hoje em dia - o que implica dizer que a situação atual também pode mudar. 
Para que a compreensão sobre as pessoas no passado ocorra, é indispensável ter acesso a fontes, isto é, restos do passado que permitem que façamos inferências sobre ele. Fontes precisam ser corretamente analisadas, o que significa dizer que precisamos conhecer o contexto de sua produção, bem como quem as produziu, por que, quando e para quem. Elas podem documentar coisas que não tencionavam documentar originalmente e permitem que façamos afirmativas sobre o passado que as pessoas que então viviam não teriam feito. ${ }^{3} \mathrm{Um}$ tratamento correto das fontes embasa o rigor histórico que buscamos nessa proposta.

Mas documentos precisam ser interrogados para se tornarem evidência de algo - é nesse esforço, justamente, que se realiza a atividade intelectual do historiador, levando à descoberta e ao conhecimento. $\mathrm{O}$ dossiê aqui proposto está estruturado em questões de pesquisa que possam fascinar, intrigar e provocar os alunos. Como também já tive oportunidade de escrever,

orientar o estudo por questões de pesquisa é fundamental na prática do ensino de história e deriva da convicção de que o aprendizado efetivo só ocorre se os alunos tiverem diante de si uma questão que precisam resolver, em vez de o professor lhes 'ensinar' a 'receita do bolo' fornecendo junto todos os ingredientes. (2010, p.94)

Trabalhar com problemas leva os alunos a selecionar, organizar e estruturar seu conhecimento a respeito do passado, como faz o historiador.

A questão de pesquisa vem acompanhada de outro processo chave que torna possível o aprendizado em história: a produção de resultados a partir do que foi investigado. Esses resultados derivam de tarefas propostas aos alunos. Por exemplo: a) julgar em que medida um conjunto de fontes responde ou não à pergunta de pesquisa (digamos, dar notas de 1 a 5), escolher as que mais se aproximam da resposta e escrever uma conclusão; b) preparar argumentos de ataque e de defesa sobre determinado assunto (por exemplo: "a política $x$ foi bem-sucedida ( foi malograda porque..."); c) identificar fontes que expressam diferentes pontos de vista sobre determinado assunto, explicar como e por que diferem. Ou seja, a pergunta problema deve levar a possíveis respostas, e é dessa forma, aprendendo a sistematizar seu conhecimento e a comunicar sobre o passado, que o aluno aprende a pensar historicamente. 
A questão de pesquisa, o uso de fontes (ou evidências) e a produção de resultados que permitam comunicar sobre o passado são três processos chave pelos quais podemos dizer que se dá o aprendizado em história. Esses requisitos são defendidos por um extenso grupo de pesquisadores da Inglaterra e dos Estados Unidos, com ramificações em outros países da Europa e também do Brasil, que, desde o final dos anos 1960, vem se perguntando sobre como ensinar a pensar historicamente. ${ }^{4}$ Ao lado dos três processos, destacam-se, de acordo com esses pesquisadores, seis conceitos chave, que não estão ligados a nenhum conteúdo histórico específico, mas são identificados como o cerne da disciplina: cronologia; diversidade; mudança e continuidade; causa e consequência; relevância; interpretação. A proposta deste dossiê também está assentada sobre as reflexões em torno desses conceitos, que serão enfatizados nas diferentes questões de pesquisa.

\section{PRINCÍPIOS NORTEADORES II: SOBRE O USO DE TICS}

Passemos agora aos pressupostos relativos ao uso de tecnologias de informação e comunicação (TICs) no ensino de história, para, em seguida, tratarmos do dossiê propriamente dito. Sabemos todos que, apesar de a aplicação dessas tecnologias no ensino trazer vantagens inquestionáveis, elas não garantem, por si sós, um melhor aprendizado. Em coletânea publicada em 2003 e intitulada História, TIC e aprendizado, o coordenador do curso de formação de professores de história da Universidade de East Anglia Terry Haydn afirma que alguns formuladores de políticas públicas consideram que a simples instalação de computadores nas escolas fará a educação melhorar. Essa ilusão decorre principalmente da formidável capacidade de transmissão pela internet de um volume enorme de informações. A metáfora que mais se ajusta a essa ideia, segundo Haydn, é a de delivery, como se houvesse uma bomba enviando coisas para dentro das escolas e dos alunos. Mas, diz o autor, transmissão de informação não é, evidentemente, o mesmo que aprendizado. E disso os bons professores estão conscientes. Uma pesquisa realizada em 1999, por exemplo, mostrou que a decisão de usar novas tecnologias depende não só da facilidade de uso dos equipamentos e de acesso a eles, mas também de os professores acharem que elas podem efetivamente ajudar a ensinar sua matéria de maneira mais eficaz. ${ }^{5}$ 
Convém explorar o potencial positivo das novas tecnologias, aproximando-nos daquilo que os professores holandeses Siep Stuurman e Maria Grever, num livro sobre as possibilidades de uma história 'pós-canônica', chamaram de 'arquivo digital', isto é, um conjunto de fontes primárias e secundárias a respeito de determinado assunto histórico, com seleção da literatura secundária que discuta as narrativas concorrentes e permita a interpretação das fontes primárias. Segundo os autores, esses 'arquivos digitais' constituem uma oportunidade ímpar de ir 'além do cânone', num momento em que o antigo livro didático, com sua apresentação monológica, não nos ajuda muito. Eles possibilitam que estudantes desenvolvam suas habilidades em situar acontecimentos em contextos mais amplos e testem interpretações, no contato direto com as fontes. Além disso, como a existência de perspectivas históricas divergentes está se tornando muito mais uma regra do que exceção (não há uma história única verdadeira sobre o passado, mas uma multiplicidade de histórias complementares ou concorrentes), o ensino de história deve se voltar para esse desafio; caso contrário, corre o risco de se tornar irrelevante. ${ }^{6}$

Esse potencial do trabalho direto com documentos tem sido enfatizado por muitos autores, em contraste com o conteúdo muitas vezes 'pronto e acabado' e 'homogeneizador' do livro didático. ${ }^{7} \mathrm{O}$ historiador Paulo Knauss também sublinha a importância do trabalho com documentos, que pode até dispensar, segundo ele, a utilização do livro didático. Para ele,

O trabalho com os documentos históricos desde cedo pode ser justamente uma fórmula para não adiarmos as tarefas que o mundo contemporâneo exige da escola - que o aluno compreenda a lógica dos meios de comunicação, especialmente os de massa, para não ser agente passivo da manobra de informações, reconhecendo outras visões de mundo, desabsolutizando-as e demarcando a sua identidade de sujeito da própria existência. ${ }^{8}$

Ou seja, o que se defende aqui é que não se utilize uma página da internet como se fosse um livro didático tradicional, com textos prontos, no estilo de apostilas, e alguns documentos servindo de ilustração. A ideia é aproveitar o potencial e o alcance das TICs para fomentar o exercício da pesquisa e o trabalho com as fontes. Nesse sentido, os pressupostos de que trata esse item coincidem com os pressupostos do próprio ensino de história, como já discutido no item anterior. $\mathrm{O}$ trabalho com documentos permite que os alunos não 
apenas ampliem seu conhecimento e estabeleçam sínteses e hierarquias, mas que reflitam sobre o próprio processo de conhecimento em história, que vem das perguntas que fazemos às fontes. Para que isso se viabilize, é fundamental fornecer informações que contextualizem os documentos: "O que é a fonte e onde se encontra?", “Como chegou até nós?”, "Em que contexto foi produzida?", “Que outras fontes nos ajudam a entendê-la?”. Os alunos também podem participar dessa contextualização, ao refletirem sobre o que elas documentam e sobre as intenções de sua produção e de sua preservação. Muitas vezes as fontes documentam aquilo que, em princípio, não tencionavam documentar - como os filmes de propaganda oficiais, por exemplo -, o que, longe de invalidar seu uso, pode trazer reflexões bem interessantes.

A vantagem das TICs está, justamente, no fato de tornarem possível disponibilizar um grande volume de documentos, em diferentes formatos, como textos, filmes, arquivos de áudio e imagens - possibilidade que um livro impresso não comporta. Mas precisamos tomar cuidado para não nos deixarmos ofuscar por essa profusão e acabar funcionando como um delivery nos termos sugeridos por Terry Haydn. Não há dúvida de que a oferta na rede é enorme hoje em dia, e só tende a aumentar. Para garantir que determinada página na internet seja usada, é aconselhável que o material oferecido seja efetivamente necessário para professores e alunos. A ideia não é disponibilizar mais uma página que o professor provavelmente salvará entre seus 'Favoritos' sem retornar a ela depois. Por isso, é preciso que o conteúdo e as atividades oferecidas sejam relevantes do ponto de vista do currículo escolar e ofereçam oportunidades de aplicação em sala e de trabalho de casa, entre outras. É importante também que professores e alunos possam imprimir os documentos ou, se quiserem, levá-los para outros aplicativos, a fim de inseri-los num exercício ou numa apresentação, por exemplo.

O aluno também deve se sentir engajado e atraído pela página. Convém selecionar documentos que surpreendam, que sejam eficazes como fontes de pesquisa e que deem um sentido de autenticidade ao que está sendo investigado. Além disso, é aconselhável facilitar a interação com o material. Por exemplo, ao lado de um documento em fac-símile, apresentação que torna concreta e palpável a relação com a fonte, pode ser indicado fornecer sua transcrição completa, para facilitar a leitura, uma transcrição simplificada, ou ainda uma 
versão em áudio do mesmo documento, lida por um locutor enquanto o texto aparece na tela. ${ }^{9}$

Finalmente, é muito importante dar autonomia aos alunos para que decidam que fontes vão usar e que caminhos vão seguir para dar conta da questão de pesquisa e produzir os resultados sugeridos. ${ }^{10}$ Eles não precisam nem mesmo utilizar todas as fontes disponibilizadas para dar conta de uma questão. Trata-se, pois, de fortalecê-los (ou, como tem sido comum dizer, 'empoderá-los'), oferecendo-lhes possibilidades de escolhas - de pontos de vista e de atividades - e estimular que dominem autonomamente os assuntos. Com isso, estaremos mais próximos de um efetivo aprendizado.

\section{O DOSSIE}

O dossiê aqui proposto teria como alvo alunos do segundo ciclo do ensino fundamental e do ensino médio, mas poderia ser útil a outros públicos também. Além de orientações para professores e de um tutorial sobre o trabalho com fontes, seu conteúdo viria dividido em unidades, que poderiam ser trabalhadas independentemente e sem necessidade de seguir a ordem de apresentação.

- Unidade I - Por que se instituiu o trabalho escravo na América Portuguesa?

Conceito chave: causalidade

Já tive oportunidade de observar que precisamos ter cuidado ao abordar o assunto 'escravidão e tráfico transatlântico' no ensino da história das relações raciais, um tema sem dúvida indispensável, mas que, isolado, pode reforçar preconceitos e não suscitar reflexão. ${ }^{11}$ Como afirma Robert Phillips, professor da Universidade de Wales Swansea, no Reino Unido:

A história da escravidão coloca inúmeros desafios para o professor de história. De um lado, a escravidão deve ser estudada para que se perceba seu papel vital na criação do racismo, mas, de outro lado, imagens constantes da subjugação dos escravos têm um potencial de simplesmente reforçar o estereótipo superior/inferior mencionado acima [entre brancos e negros]. ${ }^{12}$ 
Por essa razão, convém introduzir esta unidade com atividades que permitam colocar em xeque algumas pré-noções, como, por exemplo, a ideia de que todo negro era escravo e vice-versa e a de que, entre os séculos XVI e XIX, a alternativa à escravidão era o trabalho livre assalariado.

Algumas tarefas podem ser cogitadas aqui. Por exemplo, apresentar aos alunos imagens (pinturas, tapeçarias, esculturas etc.) de escravos negros e não negros de diferentes regiões (incluindo a Europa Ocidental e o Oriente) ao longo da história e pedir que descrevam o que veem e se perguntem o que haveria de comum nos documentos. Em seguida, seriam apresentadas as referências completas das fontes para que os alunos as ordenassem cronologicamente e refletissem sobre similaridades e diferenças entre elas. Além das imagens propriamente ditas, o material pode ser complementado com outras fontes primárias e secundárias que deem conta de diferentes exemplos e concepções de escravidão através da história. Dependendo das possibilidades oferecidas pelo material e das circunstâncias de sua aplicação, pode-se também perguntar aos alunos por que acham que lhes foi solicitado ordenar as fontes cronologicamente. Isso permite que controlem o processo de aprendizagem e reflitam, no caso específico, sobre possíveis mudanças e continuidades. Por fim, pode-se pedir que os alunos elaborem uma definição geral da escravidão e, numa etapa posterior, reflitam sobre quais perguntas ainda precisariam ser feitas para dar conta do tráfico transatlântico e da escravidão africana nas Américas - isto é, que também decidam que passos precisam ser dados para ampliarem seu conhecimento. ${ }^{13}$

Outra tarefa que pode ser útil nessa introdução gira em torno de fontes primárias e secundárias que mostrem condições de trabalho em diferentes partes do mundo entre os séculos XVI e XIX, para que os alunos possam identificar outras formas de trabalho compulsório ou em condições degradantes (por exemplo, a servidão por contrato na América inglesa, ou o trabalho infantil nas minas de carvão da Inglaterra oitocentista). Muitas vezes tendemos a transferir para o passado conhecimentos que adquirimos de nossas experiências atuais, e pode acontecer de os alunos reduzirem as relações de trabalho de outrora a apenas duas opções: a escravidão, de um lado, e o trabalho livre assalariado, de outro. Conhecer outras relações de trabalho do passado é importante para colocar em xeque a noção bastante comum de que o escravo negro é a vítima por excelência, e seu corpo, o lugar exclusivo de sofrimento e pro- 
priedade alheia. A tarefa a ser executada poderia consistir em ordenar as diferentes formas de trabalho trazidas pelas fontes num gráfico com duas coordenadas - uma que vai do trabalho 'mais livre' para o 'menos livre', e outra que vai das condições 'mais degradantes' para as 'menos degradantes'. Evidentemente, não há uma resposta inequívoca para a localização de cada um dos tipos de trabalho no gráfico, mas a atividade é interessante como exercício de comparação. Ainda que o trabalho escravo possa ser situado como o 'menos livre' e o 'mais degradante', sua situação em relação ao trabalho servil, na Rússia czarista, ou em relação àquele de serviçais de uma residência inglesa do século XIX, por exemplo, pode diminuir o risco da simplificação mencionada.

Uma vez introduzido o tema da escravidão nas Américas, cabe fornecer ao aluno possibilidades de trabalhar a questão de pesquisa proposta nesta unidade: por que se instituiu o trabalho escravo nas Américas? O importante é ter em mente que se trata da escravidão indígena e africana. Mais uma vez, a ideia é disponibilizar uma série de fontes primárias e secundárias com base nas quais se poderia começar a trabalhar. Como tarefa, pode-se sugerir aos alunos que: 1) ordenem as fontes numa espécie de gradação - fonte boa para responder à pergunta problema, fonte não tão boa para responder à pergunta; 2) escrevam, ao lado das fontes consideradas 'boas', por que elas explicam a opção pela escravidão; 3) montar um diagrama, no formato de uma pirâmide ou de um diamante, que permita ordenar as causas (as fontes, ou enunciados elaborados a partir das fontes) das menos decisivas para as mais decisivas.

Como já observado no item 2, a ideia é fornecer aos alunos uma série de opções e dar-lhes autonomia para que decidam que fontes melhor se adequam ao que foi perguntado. Se a atividade for desenvolvida com uma classe, é possível que os alunos comparem suas respostas e verifiquem se os colegas encontraram outras causas mais decisivas do que as que eles próprios puderam identificar. Não se pretende sugerir, com esse tipo de atividade, que apenas uma resposta é possível. O importante é fazer os alunos refletirem a respeito dos diferentes fatores que levaram à opção pela escravidão (africana e indígena), ao mesmo tempo em que refletem sobre a própria causalidade em história. Como sabemos, identificar causas ou fatores que levaram a certos resultados está longe de ser uma atividade simples. Muitas vezes considera-se equivocadamente que 'causas' são como peças de um dominó, que se alinham num 
único e necessário movimento para produzir determinado resultado. $\mathrm{O}$ exercício aqui proposto tem a intenção de despertar para outras possibilidades.

Entre as fontes primárias e secundárias a serem disponibilizadas nesta unidade estariam:

- Diferentes documentos mostrando que africanos eram valorizados como trabalhadores especializados na manufatura do açúcar, na pecuária extensiva, na mineração etc.

- Documentos que versam sobre as relações entre europeus e indígenas, nas Américas, incluindo escravidão indígena, missões jesuítas, escambo, defesa do território da colônia, determinações legais, extermínio.

- Fontes primárias e secundárias em torno dos lucros auferidos com o tráfico transatlântico e com atividades a ele vinculadas, como construção naval, produção de bens como tabaco, cachaça e tecidos; impostos sobre exportação e importação de escravos africanos; comparação com outras atividades lucrativas.

- Trechos extraídos de documentos de época que reproduzam diferentes concepções sobre a escravidão e o tráfico transatlântico, entre os séculos XVI e XIX, de autoria de filósofos, políticos, religiosos e comerciantes, entre outros.

Esta unidade poderia ainda incluir uma seção reunindo trechos de livros didáticos antigos e contemporâneos com diferentes explicações para a opção pela escravidão africana (por exemplo, a ideia de que o indígena não era 'adaptado' ao trabalho escravo, tão comum em livros didáticos do passado). Essa seria uma boa oportunidade para os alunos refletirem sobre a história do ensino de história e entrarem em contato, por exemplo, com um material didático que poderia ter sido usado por seus pais ou avós. O ideal seria reproduzir as páginas com as explicações e ilustrações em fac-símile e solicitar, então, aos alunos que rebatam as explicações com base nas fontes disponibilizadas no dossiê. O recurso às TICs permitiria que, ao lado de cada explicação do livro, se abrisse um campo para onde fosse possível arrastar uma citação ou fonte escolhida pelo aluno, ou ainda escrever comentários. O fato de os próprios alunos trabalharem esse material e selecionarem os argumentos contrários às explicações dos livros didáticos talvez possa instrumentalizá-los para, em outras ocasiões - em conversas com familiares ou conhecidos - rebaterem alguns 
dos preconceitos que ainda persistem em relação a esse assunto (como o do índio indolente, por exemplo).

- Unidade II - Por que não faz sentido falar de 'o índio' ou 'o negro'? Conceito chave: diversidade

O principal objetivo aqui é fazer frente à homogeneização simplificadora que geralmente está por trás de preconceitos e estereótipos. Bem sabemos que falar do 'índio' e do 'negro', ou do 'africano”, é redutor e muitas vezes impede o reconhecimento de indígenas, negros e africanos como sujeitos e agentes da história. Processo semelhante ocorre com a ideia do 'judeu como vítima', reproduzida indiscriminadamente em livros didáticos e outros recursos, quando o assunto é o holocausto. Uma das estratégias adotadas por professores e instituições voltados para o ensino do holocausto, para fazer frente a essa generalização muito próxima do estereótipo, é viabilizar o acesso à diversidade de experiências do ser judeu anterior à Segunda Guerra Mundial. ${ }^{14}$

O material nesta unidade poderia ser apresentado em dois mapas interativos - um da África e outro da América do Sul - em que estariam representados reinos, nações, grupos linguísticos etc., do século XIV ao XIX, aproximadamente. Clicando sobre um desses reinos ou grupos, o aluno teria acesso a fontes diversas, incluindo registros de tradição oral, se possível, a respeito das práticas comerciais e religiosas, da organização social e política, das formas de trabalho, da língua etc. ${ }^{15} \mathrm{~A}$ tarefa do aluno seria reunir informações de cinco grupos de cada um dos mapas e inserir as fontes a respeito em duas tabelas - uma para a África e outra para a América do Sul -, obedecendo ao cabeçalho sugerido a seguir.

\begin{tabular}{|c|c|c|c|c|}
\hline $\begin{array}{l}\text { Identificação } \\
\text { do reino/ } \\
\text { grupo: nome, } \\
\text { localização } \\
\text { geográfica e } \\
\text { temporal } \\
\text { (onde e } \\
\text { quando } \\
\text { existiu) }\end{array}$ & $\begin{array}{l}\text { Fontes sobre } \\
\text { organização } \\
\text { social e } \\
\text { política - } \\
\text { identificar as } \\
\text { fontes e } \\
\text { sintetizar o } \\
\text { que elas } \\
\text { dizem }\end{array}$ & $\begin{array}{l}\text { Fontes } \\
\text { sobre língua } \\
\text { - identificar } \\
\text { as fontes e } \\
\text { sintetizar o } \\
\text { que elas } \\
\text { dizem }\end{array}$ & $\begin{array}{l}\text { Fontes sobre } \\
\text { relações com } \\
\text { outros grupos } \\
\text { (comércio, guerra } \\
\text { etc.) - identificar } \\
\text { as fontes e } \\
\text { sintetizar o que } \\
\text { elas dizem }\end{array}$ & $\begin{array}{l}\text { O que mais eu } \\
\text { sei sobre o } \\
\text { reino/grupo- } \\
\text { identificar } \\
\text { outras fontes } \\
\text { e sintetizar o } \\
\text { que dizem }\end{array}$ \\
\hline
\end{tabular}


Dependendo dos recursos de TIC, poder-se-ia pensar em arrastar os links das fontes para as células correspondentes desse quadro.

Note-se que esta unidade teria como objetivo ampliar o conhecimento dos alunos a respeito da diversidade de experiências e de organizações encontradas no continente africano e na América do Sul entre os séculos XIV e XIX. Nesse sentido, a ênfase deve recair sobre fontes que efetivamente ampliem esse conhecimento e menos sobre documentos que reforcem preconceitos e estereótipos. O que fazer, por exemplo, com o livro de Francis de Castelnau publicado em meados do século XIX relatando a existência de uma nação de homens com cauda na África central ${ }^{16}$ Pode ser que se julgue interessante acrescentar documentos desse gênero. De todo modo, cabe ao professor certificar-se de que os alunos incorporaram bem os ensinamentos do tutorial sobre o trabalho com fontes, aprendendo a discernir o que exatamente um relato desse tipo documenta. Além disso, é bom lembrar que a fonte deve vir sempre acompanhada de informações sobre o contexto de sua produção.

\section{- Unidade III - Quão diferente era a vida no 'Brasil' de 1500 a 1888 ?}

Conceitos chave: diversidade; cronologia

Esta unidade tem como objeto a economia e a sociedade na América Portuguesa e no Brasil Imperial. Pode ser iniciada com um mapa animado da ocupação do território, incluindo grupos indígenas, pau-brasil, açúcar, quilombos, pecuária, drogas do sertão, tabaco, mineração, algodão, missões na Amazônia e no Prata, bandeirantes, vilas e cidades, rotas comerciais (incluindo monções e tropeiros), café e estradas de ferro. ${ }^{17}$ Observe-se que os quilombos são vistos aqui como formas de organização social e política, de ocupação do território e de desenvolvimento de atividade econômica equivalentes ao engenho de açúcar ou à sociedade das minas. Além de estudarmos os quilombos como exemplos de resistência à escravidão, convém percebê-los como uma entre as muitas modalidades de colonização do 'Brasil' - colonização no sentido de ocupação do território e implementação de determinadas práticas políticas, sociais, econômicas e culturais.

Como na unidade anterior, seriam disponibilizadas, no mapa, fontes primárias e secundárias a respeito de diferentes situações e práticas, abarcando relações de trabalho, comércio, atividades produtivas, organizações religiosas, 
formas de comunicação, revoltas e assim por diante. $\mathrm{O}$ aluno pode clicar sobre uma região, atividade, organização política etc., e obter um conjunto de fontes a seu respeito.

Uma das vantagens do uso de TICs em material didático, especialmente no caso de conteúdo disponibilizado na internet, é o fato de, uma vez estabelecido um padrão ou molde, sempre ser possível acrescentar novos itens àquele recurso. Assim, é evidente que um mapa que pretenda representar a diversidade de práticas sociais, políticas, econômicas e culturais de 1500 a 1888 no território que hoje é o Brasil jamais esgotará todas as possibilidades. O dossiê pode, inicialmente, apresentar algumas dessas práticas, para, conforme forem sendo encontradas e selecionadas mais informações e fontes, estas sejam acrescentadas ao mapa.

A atividade sugerida para esta unidade é uma espécie de jogo da generalização, no qual alunos formulam afirmativas convincentes, mas incorretas, sobre assuntos abarcados no mapa (por exemplo: "Todos os quilombos ficavam distantes das vilas”) e desafiam os colegas a descobrirem onde está a generalização, com base nas fontes disponibilizadas no mapa. O colega que descobrir, pode denunciar: "Não é tão simples!", e apontar onde está a generalização. Em seguida, os alunos podem refletir sobre uma redação mais apropriada (por exemplo: "Nem todos os quilombos ficavam distantes das vilas, como mostra o exemplo $x$, que..."). ${ }^{18}$

- Unidade IV - O que as biografias de africanos escravizados e seus descendentes podem dizer sobre seus personagens e o mundo em que viveram?

Conceitos chave: cronologia; relevância; diversidade

O uso de biografias no estudo da história permite tornar concretas experiências vividas no passado, bem como colocar em xeque visões generalizadas a respeito de trajetórias e modos de vida que desconhecemos. ${ }^{19}$ Aqui podem ser usadas as biografias de Rosa Egipcíaca (1719-1778), Olaudah Equiano (c.1745-1797), Ottobah Cugoano (c.1757-após 1791), Maria Jesuína de Zomadonu (antes de 1797-após 1840), Mahommah Baquaqua (c.1824-após 1854), Luiz Gama (1830-1882) e outros. Como um dos conceitos chave sugeridos para esta unidade é 'relevância', cabe introduzir também a discussão de por que determinados personagens históricos são lembrados, e outros não, ou se- 
ja, o que, em história, é considerado 'relevante' (o que implica perguntar: "Relevante para quem e por quê?").

Mais uma vez, trata-se de fornecer aos alunos um conjunto de fontes com base nas quais deverão executar as tarefas propostas. Nesta unidade, as fontes se referem a cada um dos personagens estudados - seleção de textos escritos sobre e pelos personagens, entre os quais biografias e autobiografias, descrições de locais por onde passaram, imagens de época, retratos etc.

Os alunos serão convidados a realizar três tarefas. A primeira, uma linha do tempo desenhada num mapa-múndi, acompanhando a trajetória de vida e os deslocamentos de cada personagem. Caberá aos alunos traçar a trajetória no mapa e, sempre que necessário, abrir um registro para inserir um dado ou acontecimento novo. Cada registro deve compreender uma explicação e um link para a fonte da informação. Por exemplo, um registro aberto pelo aluno na altura de Salvador informaria: "Nascimento de Luiz Gama em 21 de junho de 1830, em Salvador".

Reconstituídas as trajetórias de vida, a tarefa seguinte consiste em avaliar o alcance e os limites das principais fontes utilizadas na elaboração da linha do tempo, perseguindo a resposta da questão de pesquisa inicial. Solicita-se que os alunos preencham este quadro:

\begin{tabular}{|l|l|l|l|l|}
\hline $\begin{array}{l}\text { O que sei sobre a } \\
\text { fonte: o que é, } \\
\text { quem é o autor, } \\
\text { quando produziu } \\
\text { a fonte e, se for } \\
\text { possível, por quê } \\
\text { (suas intenções) }\end{array}$ & $\begin{array}{l}\text { O que a fonte } \\
\text { me diz sobre o } \\
\text { personagem } \\
\text { da biografia }\end{array}$ & $\begin{array}{l}\text { O que a fonte } \\
\text { permite inferir } \\
\text { sobre o mundo } \\
\text { à época em que } \\
\text { o personagem } \\
\text { viveu }\end{array}$ & $\begin{array}{l}\text { O que } \\
\text { mais a } \\
\text { fonte me } \\
\text { diz }\end{array}$ & $\begin{array}{l}\text { O que a fonte } \\
\text { não me diz e } \\
\text { como posso } \\
\text { saber mais } \\
\text { sobre isso }\end{array}$ \\
\hline & & & & \\
\hline
\end{tabular}

A última tarefa seria uma composição das duas primeiras: escrever uma apresentação do personagem, discutindo sua relevância para o estudo da história e comentando aquilo que sua biografia permite e aquilo que não permite afirmar. Com esse exercício ficaria bastante claro para os alunos que os conhecimentos que temos do passado são condicionados pelas fontes de que dispomos e dependem das perguntas que a elas fazemos. É importante notar - e desejável que os alunos também percebam isso - que esse constrangimento não significa necessariamente uma limitação do nosso conhecimento, mas 
constitui um elemento fundamental para avaliar o que passamos a conhecer (e que não conheceríamos sem as fontes).

- Unidade V - Por que é tão difícil afirmar quando acabou a escravidão indígena no Brasil?

Conceitos chave: mudança e continuidade; interpretação

A escravidão indígena é um assunto pouco tratado e bastante nebuloso, no ensino da história do Brasil. Durante muito tempo, como observa o historiador e indigenista André Raimundo Ferreira Ramos, costumava-se dizer que o indígena não foi escravizado, ou, se muito, que a escravidão indígena ocorrera apenas no início da colonização. Era comum os livros didáticos pularem do escambo diretamente para as missões jesuíticas, como se o trabalho escravo indígena tivesse sido totalmente substituído pelo africano, esquecendo-se assim que diferentes modalidades regionais de escravidão indígena perduraram, seguramente, até o final do século XIX. ${ }^{20} \mathrm{O}$ conceito chave 'mudança e continuidade' aplica-se bem à pergunta desta unidade, pois nela está embutida a questão dos limites da mudança: o 'fim' da escravidão indígena significou um 'fim' para quem, exatamente? Até que ponto a regra da 'guerra justa' ou a legislação pombalina de meados do século XVIII, para citar apenas duas determinações portuguesas, constituíram rupturas efetivas?

As fontes no caso desta unidade incluem diferentes atos da legislação indígena desde o início da colonização, determinações administrativas, relatos de viajantes e relatórios, que deem conta de relações de trabalho praticadas pelo menos até finais do século XIX. ${ }^{21}$ Para que os alunos possam visualizar as mudanças e continuidades, e refletir sobre elas, poderiam começar ordenando as fontes cronologicamente e resumindo seu conteúdo, como proposto neste quadro:

\begin{tabular}{|l|l|}
\hline $\begin{array}{l}\text { Especificar a fonte: o que é, quando, por quem e por que foi } \\
\text { escrita }\end{array}$ & O que diz a fonte \\
\hline & \\
\hline
\end{tabular}

Em seguida, os alunos poderiam fazer um exercício de redação, comparando os resultados de sua pesquisa com trechos de livros didáticos antigos e atuais. Para tanto, poderia ser disponibilizada uma espécie de molde para a redação de um ensaio, com espaços que seriam completados pelo aluno com 
base em suas pesquisas, semelhante ao que pode ser encontrado na página do Arquivo Nacional Britânico. ${ }^{22} \mathrm{O}$ molde começaria com uma introdução genérica, a ser completada pelo aluno e, na sequência, apresentaria espaços para incluir trechos encontrados em livros didáticos e objeções a eles, baseadas nas fontes estudadas. Cada trecho e fonte citados no ensaio do aluno já viriam acompanhados de sua respectiva referência bibliográfica, na forma de notas de pé de página. A estrutura acompanharia este roteiro:

1. Introdução genérica: Há muita incorreção em manuais escolares e em outras publicações, e até nas noções do senso comum, sobre a escravidão indígena no Brasil. [deixar espaço para o aluno continuar o parágrafo introdutório]

2. O [trecho de manual escolar] de [data], por exemplo, afirma que...

3. Mostrar o que pode estar correto, nessa afirmação

4. Mostrar o que não está correto, nessa afirmação, e basear a argumentação em fontes examinadas na tarefa anterior

5. Mostrar o que está faltando na afirmação e basear a argumentação em fontes examinadas na tarefa anterior

6. Acrescentar outro trecho de manual escolar e proceder da mesma forma

7. No final, redigir parágrafo conclusivo

Esta seria uma ótima oportunidade para os alunos comunicarem sobre o passado utilizando uma ferramenta que permite contrapor afirmativas talvez pouco criteriosas a informações extraídas de fontes de pesquisa. O principal conceito chave em jogo na execução dessa tarefa é o de 'interpretação'; os alunos teriam oportunidade de avaliar um conjunto de interpretações sobre o passado para verificar sua validade.

- Unidade VI - O Brasil foi o último país das Américas a abolir a escravidão. Por que levou tanto tempo?

Conceitos chave: cronologia; mudança e continuidade

Há diferentes possibilidades de abordar a questão de pesquisa desta unidade. O conceito chave parece ser, mais uma vez, o de mudança e continuidade, chamando talvez mais atenção para as permanências do que para as rup- 
turas. Para que o aluno domine o assunto, podemos começar com um exercício de fixação das diferentes medidas administrativas e legais tomadas desde 1807, quando o tráfico transatlântico foi extinto na Inglaterra, até 1888 - ou então desde 1791, quando se iniciou o processo de independência do Haiti, passando pela abolição da escravidão nas colônias da França revolucionária, em 1794. Além de abarcar os documentos legais geralmente evocados - como a Lei de 1831, a Lei Euzébio de Queiroz, a Lei do Ventre Livre e a dos Sexagenários -, essa seção poderia conter informações sobre medidas legais de países da América Latina, ou de outras regiões julgadas relevantes.

Um exercício de fixação possível seria o de apresentar aos alunos três conjuntos de dados: 1) informações completas sobre as resoluções administrativas e legais relativas à extinção do tráfico transatlântico e à abolição da escravidão em diferentes regiões do mundo e do Brasil, acompanhadas da reprodução na íntegra dos documentos; 2) um resumo das resoluções sem data; 3) apenas as datas das resoluções. A tarefa seria combinar os resumos e as datas e alinhá-los numa linha do tempo. Para executá-la, seria necessário ler os documentos na íntegra, ou as informações completas. Fornecer informações relativas ao Brasil ao lado das que dizem respeito a outras regiões do mundo permite que o aluno compreenda a articulação entre ambas, o que é especialmente importante em relação ao assunto desta unidade.

Costumamos conceber a abolição do tráfico transatlântico e da escravatura como um processo que culmina com o fim da escravidão - tanto que muitas vezes chamamos esse 'processo' de 'transição do trabalho escravo para o trabalho livre'. Podemos nos perguntar se, pensando dessa forma, não estamos transportando para o passado valores e práticas do presente, quase como se fosse óbvio que a escravidão acabaria. Para dar conta justamente das dificuldades desse 'processo', é importante sublinhar as resistências ao fim da escravidão e as opiniões favoráveis à sua continuidade, vindas de fazendeiros, comerciantes e homens públicos, por exemplo. Assim, seria interessante viabilizar a elaboração de uma segunda linha do tempo, que revelasse não a mudança, mas a continuidade de atitudes em relação à escravidão no século XIX - extratos de cartas, panfletos, debates parlamentares etc., a serem inseridos na ordem cronológica, mantendo-se como contraponto as informações já compiladas para a primeira linha do tempo desta unidade. 
Outra possibilidade é debruçar-se sobre a pergunta "Quem era a favor da Abolição e quem era contra, e por quê?". As fontes aqui seriam reportagens de jornal, textos e propagandas a favor e contra, debates parlamentares, biografias de personagens que se destacaram nas campanhas etc. Como resultado, poder-se-ia propor aos alunos que preparassem uma apresentação de PowerPoint, seguindo ou não um modelo previamente elaborado. ${ }^{23}$ Os slides do PowerPoint podem ser montados a partir de perguntas como estas: "Quais eram os principais argumentos a favor da abolição?", "Quem eram os abolicionistas e como agiam?", "Quem era contra a abolição e por quê?”.

Uma questão recorrente nesse debate é a que envolve a pressão da Inglaterra para que o Brasil abolisse o tráfico transatlântico. A pergunta pode ser explorada numa seção especial da unidade, fornecendo-se, para isso, fontes primárias (correspondência oficial, legislação, tratados, documentos de fazendeiros de colônias inglesas no Caribe) e secundárias que revelem diferentes momentos e formas de atuação do governo britânico em relação a esse ponto. Ainda hoje é comum ouvirmos dizer que o interesse inglês estaria na formação de um mercado consumidor, mas isso não explica por que a pressão do governo britânico teve como foco principalmente o fim do tráfico transatlântico, e menos da escravidão em si. A tarefa aqui poderia ser, mais uma vez, comparar as informações trazidas pelas fontes com afirmações encontradas em livros didáticos. O resultado pode ser o preenchimento de um quadro como este:

\begin{tabular}{|l|l|l|l|}
\hline $\begin{array}{l}\text { Trecho do livro didático } \\
\text { sobre o assunto }\end{array}$ & $\begin{array}{l}\text { O que pode } \\
\text { estar correto }\end{array}$ & $\begin{array}{l}\text { O que está } \\
\text { incorreto }\end{array}$ & $\begin{array}{l}\text { O que está } \\
\text { faltando }\end{array}$ \\
\hline & & & \\
\hline
\end{tabular}

Outro elemento importante para dar conta desta unidade é o fato de apenas $5 \%$ da população brasileira ser escrava em 1888, o que mostra, de forma bastante incisiva, que havia muito mais negros livres e libertos do que escravos, antes do 13 de Maio. As fontes aqui podem apresentar estimativas da população escrava no século XIX, as abolições em províncias como Amazonas, Ceará e Rio Grande do Sul (uma pergunta de pesquisa bem interessante pode ser por que a abolição ocorreu nesses estados quatro anos antes de no restante do país), processos de libertação como os que eram defendidos por Luiz Gama, diferentes modalidades de alforria, inclusive as obtidas por pecúlio dos próprios es- 
cravos, exemplos de famílias negras com recursos, como as dos irmãos Rebouças e outras fotografadas pelo fotógrafo Militão, cotidiano e subsistência em comunidades negras rurais etc. A ideia é apresentar africanos e seus descendentes como senhores de seu destino muito antes de 1888 .

Pode-se acrescentar a esse conjunto de fontes documentos que indiquem que, mesmo livre ou liberto, o negro estava sujeito a restrições importantes e não raro corria o risco de ser escravizado. O Código Criminal de 1831 e o exemplo de Luiz Gama podem ser fontes eloquentes, entre outras.

A atividade a ser desenvolvida em relação a esta seção da unidade poderia ser, mais uma vez, uma redação seguindo um molde pré-elaborado, como já sugerido para a Unidade $\mathrm{V}$. O molde começaria novamente com uma introdução genérica, a ser completada pelo aluno, e teria espaço para a inserção de exemplos aprendidos com o material oferecido.

1. Introdução genérica: Ao contrário do que muitos pensam, a abolição da escravidão em 1888 não foi o momento em que a maioria dos africanos escravizados e seus descendentes se tornou livre no Brasil. Antes de 1888, grande parte dos que haviam vindo como escravos ou nascido como escravos era livre. As formas de conquistar a liberdade até 1888 variaram bastante [deixar espaço para o aluno continuar o parágrafo introdutório]

2. O documento ... mostra que era possível tornar-se livre... [descrever o caso]

3. Outra forma de alcançar a liberdade era..., como mostra o documento..., que se refere ao caso de ... [descrever o caso]

4. Os negros livres e libertos exerciam diferentes atividades, na sociedade imperial. [identificar uma pessoa ou um grupo], por exemplo, que vivia[m] em [identificar o lugar] durante [informar quando], [descrever o que fazia $(\mathrm{m})$ ]

5. Outro exemplo interessante é o de [descrever o exemplo]

6. Apesar desses exemplos, a pessoa negra ou mulata que tinha nascido livre ou tinha alcançado a liberdade corria o risco de ser considerada escrava, como mostra o documento... [descrever o caso] Esse risco deixou de existir em 1888, quando a escravidão foi abolida por lei.

7. No final, parágrafo conclusivo.

A tarefa conclusiva desta unidade poderia ser a elaboração de um texto para responder à questão de pesquisa lançada no início, sobre por que demo- 
rou tanto tempo para a escravidão ser abolida no Brasil. Uma forma de ajudar os alunos a esquematizar seu texto seria fornecer cartões com dados e/ou afirmativas extraídos das fontes utilizadas na unidade, e sugerir que, discutindo com alguns colegas, arranjem os cartões na forma de um mapa mental. Seria interessante fornecer também alguns cartões em branco, para que os próprios alunos os completem com dados e afirmativas que considerem igualmente relevantes. Uma vez selecionados os cartões que integrarão o mapa mental e definido o arranjo - isto é, a natureza das relações entre as informações consideradas relevantes -, os alunos podem se voltar para a redação do ensaio sobre a questão proposta.

\section{- Unidade VII - A raça ou cor teve/tem importância no Brasil?}

Conceitos chave: interpretação, mudança e continuidade

De uns anos para cá estabeleceu-se, no meio intelectual brasileiro, uma espécie de polarização no que diz respeito à reflexão sobre a questão racial. Antropólogos, historiadores e cientistas sociais, entre outros, têm defendido seja a implementação de ações afirmativas e mecanismos de correção das desigualdades raciais, seja a completa impropriedade dessas iniciativas, que trariam consigo o risco de divisão racial da sociedade. Esta unidade objetiva qualificar os alunos a participarem dessa discussão, familiarizando-os com os argumentos e trazendo algumas informações sobre a história do conceito de raça no Brasil e no mundo, inclusive sua invenção e posterior 'desinvenção' pela biologia.

O material seria composto por uma seleção de textos de diferentes autores, desde Nina Rodrigues, passando por defensores do 'branqueamento', por Manuel Bonfim, Lima Barreto, Gilberto Freyre, Oracy Nogueira, Florestan Fernandes e outros, editoriais da imprensa negra e documentos de organizações do movimento negro, letras de música e pinturas relativas ao tema, manifestos contra e a favor das ações afirmativas e do Estatuto da Igualdade Racial publicados desde 2006, entre outros.

Numa primeira etapa, pode-se solicitar aos alunos que completem 'etiquetas' dos documentos, conforme os fossem consultando. As etiquetas estariam ligadas às fontes e teriam um campo já preenchido (o título do documento) e espaço para o preenchimento de quatro outros campos. 


\begin{tabular}{|c|c|c|c|c|}
\hline $\begin{array}{l}\text { Título do } \\
\text { documento [essa } \\
\text { seria a única } \\
\text { informação que } \\
\text { já viria na } \\
\text { 'etiqueta']. }\end{array}$ & $\begin{array}{l}\text { Informação sobre o } \\
\text { tipo de documento: } \\
\text { do que se trata (artigo } \\
\text { de jornal, letra de } \\
\text { música, trecho de } \\
\text { livro, entrevista etc.) }\end{array}$ & Data & $\begin{array}{l}\text { Autor e } \\
\text { local de } \\
\text { publicação }\end{array}$ & $\begin{array}{l}\text { Resumo de três } \\
\text { linhas, aproxima- } \\
\text { damente, infor- } \\
\text { mando o que diz } \\
\text { o documento }\end{array}$ \\
\hline & & & & \\
\hline
\end{tabular}

Num segundo momento, as etiquetas e seus documentos poderiam ser arrastados para uma linha do tempo, com o objetivo de suscitar reflexões sobre possíveis mudanças nas concepções em torno da questão racial no Brasil. Dependendo do material reunido, pode ser possível acompanhar diferentes opiniões sobre raça e cor no Brasil, desde a ênfase na degenerescência da população brasileira em razão da presença maciça dos negros, passando pelo ideal do branqueamento e, em seguida, da mestiçagem, até a denúncia do racismo e das desigualdades raciais e a polarização em torno das medidas a serem adotadas.

Outra possibilidade seria acrescentar uma coordenada vertical à linha do tempo (que permaneceria na horizontal), que indicasse 'mais' ou 'menos' preconceito. Os documentos e suas etiquetas seriam então dispostos nesse gráfico, conforme se pudesse inferir que defendem ou pressupõem uma hierarquia (superior-inferior) entre brancos e não brancos, ficando claro que nem todos os documentos poderiam ser classificados dessa forma.

Em seguida, pode-se solicitar que os alunos separem do material fornecido os documentos que tratam especificamente da discussão sobre ações afirmativas e os dividam entre os que são a favor e os que são contra. $\mathrm{O}$ passo seguinte seria examinar os argumentos, seus pontos fracos e fortes, e propor um debate entre os alunos, virtual ou presencialmente. Alguns autores apontam, aliás, que debates virtuais muitas vezes rendem mais do que os que são conduzidos em sala de aula, quando os alunos às vezes não expressam suas opiniões com liberdade, seja porque receiam não terem um bom desempenho, seja porque não querem ferir os colegas. ${ }^{24}$

\section{- Unidade VIII - Movimentos negros e indígenas são ‘separatistas’?} Conceito chave: interpretação

Esta unidade é complementar à anterior. A ideia é apresentar, num mapa interativo do Brasil, diferentes organizações negras e indígenas existentes des- 
de o final do século XIX. Quando o aluno clica sobre uma organização, tem acesso a uma breve informação sobre ela e a diferentes fontes - artigos, manifestos, pôsteres, fotografias, filmes, gravações sonoras, entrevistas etc. A tarefa consiste em escolher alguns desses movimentos para preencher este quadro:

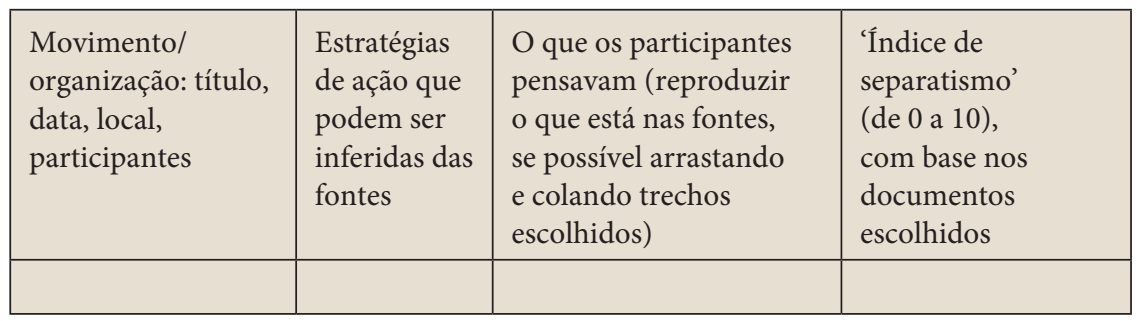

O preenchimento da última coluna pode ser aprimorado com um debate em sala. O professor distribui cartões com os nomes dos movimentos ou organizações, nos quais cada aluno escreve seu 'índice de separatismo', o qual discutirá em três etapas com seus colegas: com alguém que escolheu um 'índice' parecido, com alguém que tem um índice pouco diferente e, finalmente, com alguém que escolheu um índice bem diferente. Após cada discussão, o aluno reflete se desejaria mudar seu índice e, no final, uma discussão do plenário tenta fixar os pontos principais.

Essa atividade e a questão de pesquisa que lhe serve de pano de fundo objetivam lidar com a polarização decorrente da atuação dos movimentos sociais e da reação a eles. Muitos professores já devem ter ouvido críticas em formas de perguntas, como "Por que não existe um Dia da Consciência Branca?”, ou “Por que é obrigatório estudar África, mas não é obrigatório estudar o Japão, por exemplo?”. Trata-se de questões delicadas, mas isso não deve ser razão para que não sejam tratadas nas aulas de história. Aliás, como já dissemos, é preciso justamente enfrentar essas e outras questões sensíveis e controversas nas nossas aulas, pois do contrário nossa disciplina corre o risco de se tornar irrelevante. ${ }^{25}$

\section{- Unidade IX - A raça ou cor teve/tem importância fora do domínio europeu?}

Conceitos chave: diversidade, cronologia

Esta unidade tem o objetivo de chamar a atenção para o olhar não europeu sobre outros povos. Interessa aqui pesquisar se e como pessoas de diferen- 
tes lugares do mundo explicaram e explicam diferenças que, no mundo ocidental, foram chamadas de 'raciais', e se essas explicações implicaram julgamentos do tipo superior/inferior. Como os habitantes do continente indiano viam os chineses, ou os africanos da costa oriental? Como os portugueses eram representados em placas que decoravam os pilares do palácio do reino de Benin, no século XVI?26 $\mathrm{O}$ interessante seria reunir um conjunto de documentos de diferentes regiões e épocas que possam dar conta desses encontros ou desencontros entre povos. É claro que o material terá de ser muito bem contextualizado, pois muitas vezes só temos acesso à visão do não europeu desde o relato de um europeu, e esse viés da informação precisa estar bem esmiuçado. As fontes podem estar dispostas num mapa-múndi e, como nos exemplos anteriores, ser acessadas por um clique.

Como atividade, poderíamos propor duas tarefas. Uma primeira decorreria da análise das fontes selecionadas pelo aluno, e seguiria, por exemplo, esta orientação:

\begin{tabular}{|l|l|l|}
\hline $\begin{array}{l}\text { Sobre a fonte: título (o } \\
\text { aluno pode atribuir } \\
\text { um título), local, data, } \\
\text { por quem e por que foi } \\
\text { produzida? }\end{array}$ & $\begin{array}{l}\text { Que cuidados preciso tomar para interpretar } \\
\text { essa fonte? (Por exemplo, que cuidados } \\
\text { precisamos tomar com a reprodução do } \\
\text { diálogo com um tupinambá por Jean de } \\
\text { Léry, na década de 1550?) }\end{array}$ & $\begin{array}{l}\text { O que a } \\
\text { fonte me } \\
\text { diz? }\end{array}$ \\
\hline & & \\
\hline
\end{tabular}

A segunda tarefa seria a preparação de um PowerPoint, com a apresentação de alguns achados por parte do aluno, seguindo talvez um molde previamente preparado. Os alunos podem apresentar os PowerPoints em sala, para socializar suas descobertas. Para isso, talvez fosse interessante dividir a turma em grupos e estabelecer uma região do mapa para cada grupo. Assim, as apresentações trariam novidades para a turma.

\section{- Jogo - Brasileiros notáveis}

O dossiê poderia conter atividades lúdicas. Uma possibilidade seria uma espécie de jogo da memória em que se apresentassem imagens, dados biográficos e algumas obras (quadros, músicas, trechos de filmes, de livros etc.) de cientistas, músicos, engenheiros, políticos, médicos, artistas plásticos e escritores, entre outros, mulheres e homens de diversas origens e aparências, com 
o intuito de acostumar os alunos à existência, entre os notáveis, de negros e indígenas. O objetivo do jogo seria juntar corretamente os três elementos referentes a uma pessoa (sua imagem, seus dados biográficos e suas obras), e quem conseguisse acumular o maior número de associações corretas seria o vencedor. Uma ideia interessante é fornecer ferramentas para que o aluno acrescente mais 'notáveis' ao jogo, inclusive ele mesmo, amigos e parentes, com as respectivas imagens, os dados biográficos e as obras.

\section{OBSERVAÇões FINAIS}

A maioria das sugestões descritas nesta proposta não precisa, evidentemente, de TICs para ser colocada em prática. Um barbante com pregadores pode servir de linha do tempo, e cartolinas podem dar origem a tabelas nas quais se colam imagens ou trechos de documentos. Talvez o maior trabalho, para o professor, seja a pesquisa e a seleção de fontes adequadas, que sirvam ao seu propósito de forma honesta em relação ao passado, isto é, como sublinhei no início, priorizando o rigor histórico. Não há dúvida de que a atividade docente é uma atividade de pesquisa por excelência, pois necessita de objetivos a serem definidos ("O que exatamente eu gostaria que meus alunos aprendessem?"), etapas e métodos a serem trilhados (“Como fazer com que eles aprendam?”) e resultados a serem alcançados (“Como saberei que eles sabem?").

Todo professor saberá escolher, das ideias aqui apresentadas, aquelas que mais se adaptam a sua sala de aula e a sua instituição de ensino. Dependendo da disponibilidade de tempo, poderá encontrar fontes interessantes nos arquivos de sua cidade ou em repositórios de documentos na internet. O importante é refletirmos bem sobre o que exatamente pretendemos com a aplicação das Leis 10.639 e 11.645, e como alcançar nossos objetivos. As possibilidades são infinitas, o que é ótimo, mas precisamos também de muita cautela para não desperdiçar oportunidades. O trabalho é difícil, lento, e a toda hora somos lembrados de sua premência.

Como outro dia, em que vivi uma situação simples que, com certeza, poderia ter ocorrido em qualquer sala de aula do país. Era minha primeira aula numa turma do $2^{\circ}$ ano do Ensino Médio e, como costumo fazer, tentei transmitir aos alunos minha convicção de que precisamos conhecer o passado como forma de nos 'alfabetizar' na 'leitura do mundo'. Um exemplo que gosto de dar, tomando cuidado para não generalizar, pois o assunto é muito sério, 
é dos judeus que perceberam que precisavam sair da Alemanha antes do holocausto - digo aos alunos que é importante estar 'alfabetizado no mundo' para talvez compreender alguns sinais e tomar decisões. É um exemplo radical, mas eu me permito ser um pouco radical quando se trata de defender a importância da matéria! Uma aluna então perguntou se havia sido a primeira grande perseguição aos judeus no mundo, e acabamos caindo no assunto dos cristãos-novos, que, para não serem perseguidos pelos impérios português e espanhol, mudaram de religião e de nome - 'Oliveira', 'Pereira' etc. Esse é um exemplo clássico, que os alunos em geral já conhecem. Outra aluna sugeriu que o sobrenome 'Costa' também deveria ser de cristão-novo. Expliquei que já ouvira falar que 'Costa' era um sobrenome comum a descendentes de escravos africanos, os negros 'da Costa', e até desenhei no quadro a costa ocidental da África para ajudar a visualizar a informação. Nesse ínterim, um celular tocou (todos também já experimentamos essa situação), e os alunos começaram a rir. Perguntei: "Por que estão rindo? Por causa do celular?". "Não", foi a resposta, "é porque ele" - apontaram um colega - "é Costa". E eu disse: "Interessante, vocês estão rindo porque ele é 'Costa'? E se ele fosse 'Oliveira', ou 'Pereira'? Também ririam? E 'Smith'?".

Como disse, foi um episódio simples, que poderia ter acontecido em qualquer sala de aula do país, independentemente da cor dos alunos. Não era uma aula sobre África ou sobre história e cultura afro-brasileira. Era uma aula sobre história, simplesmente. E me forneceu material para refletir - a ponto de eu ter decidido relatá-lo aqui. Ele mostra como é fundamental tratarmos das ideias sobre raça e cor no Brasil e da história das relações étnico-raciais. Sempre respeitando os alunos e seus preconceitos - quase podemos dizer que eles não têm culpa do que sentem e pensam. Cabe a nós, professores, tentar mudá-los a esse respeito. Uma das formas de fazê-lo é a que defendo neste texto: disponibilizar cada vez mais material útil e de qualidade, que talvez possa, com repetições, insistência e vontade, derrubar preconceitos, a ponto de se tornar quase impossível rir de um colega com sobrenome 'Costa'.

\section{NOTAS}

${ }^{1}$ Este texto é parte dos resultados de minha pesquisa de pós-doutorado na área de ensino de história, realizada na Inglaterra, na University of East Anglia e no Institute of Education da University of London, durante o ano de 2009. Agradeço à Coordenação de Aperfeiçoa- 
mento de Pessoal de Ensino Superior (Capes) a concessão de uma bolsa de pós-doutoramento, bem como ao Centro de Pesquisa e Documentação de História Contemporânea do Brasil (CPDOC) da Fundação Getulio Vargas, Rio de Janeiro, a licença concedida.

${ }^{2}$ Ver, a respeito, ALBERTI, Verena. O ensino de história na Inglaterra: conceitos e práticas. In: FERREIRA, Marieta de Moraes (Org.) Memória e identidade nacional. Rio de Janeiro: Ed. FGV, 2010. p.81-100.

${ }^{3}$ Ver também ALBERTI, cit.

${ }^{4}$ Os três processos e os seis conceitos fazem parte, por exemplo, do currículo oficial de história no Reino Unido. Disponível em: www.education.gov.uk/schools/teachingandlearning/curriculum/secondary/b00199545/history/programme; Acesso em: 30 jan. 2012. Para esse debate, ver meu texto já citado na nota 2 e as referências nele contidas. No Brasil, participam do debate, entre outros, Maria Auxiliadora Schmidt, da Universidade Federal do Paraná, e Margarida Maria Dias de Oliveira, da Universidade Federal do Rio Grande do Norte.

${ }^{5}$ HAYDN, Terry. Computers and History: rhetoric, reality and the lessons of the past. In: HAYDN, T.; COUNSELL, C. (Ed.) History, ICT and Learning in the Secondary School. London: Routledge Falmer, 2003. p.13-16.

${ }^{6}$ STUURMAN, S.; GREVER, M. Introduction: Old canons and new histories. In: Beyond the Canon: history for the $21^{\text {st }}$ century. New York: Palgrave Macmillan, 2007. p.1-16. Ver também: LEE, Peter. Understanding history. In: Canadian Historical Consciousness in an International Context: theoretical frameworks. Vancouver: Centre for the Study of Historical Consciousness, University of British Columbia, Aug. 2001. Disponível em: dc122.4shared.com/doc/v1wIolio/preview.html; Acesso em: 6 mar. 2012.

${ }^{7}$ Críticas ao caráter homogeneizador do livro didático podem ser encontradas em BITTENCOURT, Circe. Livros didáticos entre textos e imagens. In: BITTENCOURT, C. (Org.) O saber histórico na sala de aula. 11.ed. São Paulo: Contexto, [1997] 2006. p.69-90; MUNAKATA, Kazumi. O livro didático e o professor: entre a ortodoxia e a apropriação. In: MONTEIRO, Ana Maria; GASPARELLO, Arlette Medeiros; MAGALHÃES, Marcelo de Souza (Org.) Ensino de história: sujeitos, saberes e práticas. Rio de Janeiro: Mauad; Faperj, 2007. p.137-147; e ABUD, Katia Maria. A história nossa de cada dia: saber escolar e saber acadêmico na sala de aula. In: MONTEIRO; GASPARELLO \& MAGALHÃES (Org.), 2007, p.107-117.

${ }^{8}$ KNAUSS, P. Sobre a norma e o óbvio: a sala de aula como lugar de pesquisa. In: NIKITIUK, Sonia Maria Leite (Org.) Repensando o ensino de história. 6.ed. São Paulo: Cortez, [1996] 2007. p.29-50. (Coleção Questões da nossa época, 52). p.48.

${ }^{9}$ Exemplos interessantes podem ser encontrados em www.nationalarchives.gov.uk/education/focuson/domesday/default.htm; www.nationalarchives.gov.uk/education/ lessons/2358-popup.htm; www.nationalarchives.gov.uk/education/worldwar2/theatres-of-war/western-europe/investigation/resistance/sources/docs/4c/ (ver "listen to this document", na parte inferior do documento); Acessos em 31 jan. 2012. 
${ }^{10}$ Ver a caixa de fontes ("source box") deste exemplo: www.nationalarchives.gov.uk/education/worldwar2/theatres-of-war/western-europe/investigation/d-day/sources/; Acesso em: 31 jan. 2012.

${ }^{11}$ ALBERTI, Verena. "Algumas estratégias para o ensino de história e cultura afro-brasileira”. Artigo no prelo, a ser publicado no livro Ensino de história e diversidade, organizado por Amilcar Araujo Pereira e Ana Maria Monteiro, como parte das atividades do Laboratório de Estudos e Pesquisas em Ensino de História (Lepeh/UFRJ).

${ }^{12}$ PHILLIPS, Robert. Historical significance - the forgotten 'Key Element'. Teaching History 106: Citizens \& Communities. Historical Association, Mar. 2002, p.14-19, p.18. Disponível para membros da Historical Association em www.history.org.uk/resources/secondary_resource_869_12.html; Acesso em: 3 jul. 2011. (Tradução nossa).

${ }^{13}$ Essa proposta de introdução ao tema foi sugerida por um grupo de três alunos do curso de formação de professores de história do Institute of Education (IoE) da University of London de que tive oportunidade de participar durante meu estágio de pós-doutorado. A sugestão foi apresentada na aula de 26/10/2009, que tinha como foco a avaliação do processo de aprendizagem pelos próprios alunos.

${ }^{14}$ Já tive oportunidade de explorar essa questão em: 1) ALBERTI, Verena. "História e memória na sala de aula e o ensino de temas controversos", artigo no prelo a ser publicado na trilogia História, memória e o ensino das ditaduras do século $X X$, coletânea organizada por Samantha Viz Quadrat, Denise Rollemberg e Alessandra Carvalho, da Universidade Federal Fluminense; 2) ALBERTI, Verena. “Algumas estratégias para o ensino de história e cultura afro-brasileira”, artigo no prelo a ser publicado no livro Ensino de História e Diversidade, cit.; e 3) ALBERTI, Verena. Oral history interviews as historical sources in the classroom. Words \& Silences. The Journal of the International Oral History Association. The Workings of Oral History, v.6, n.1, p.29-36, Dec. 2011. ISSN 1405-6410 Online ISSN 22224181. Disponível em: wordsandsilences.org/index.php/ws/issue/view/4/showToc.

${ }^{15}$ Fontes interessantes podem ser encontradas em www.wdl.org/pt/; Acesso em: 31 jan. 2012.

${ }^{16}$ Publicado no Brasil como CASTELNAU, Francis de. Entrevistas com escravos africanos na Bahia oitocentista. Rio de Janeiro: J. Olympio Ed., 2006.

${ }^{17} \mathrm{Um}$ bom exemplo de mapa animado encontra-se em www.nationalarchives.gov.uk/education/worldwar2/theatres-of-war/western-europe/1939/index.htm; Acesso em: 31 jan. 2012.

${ }^{18} \mathrm{O}$ jogo da generalização, também chamado “Too simple game”, foi proposto por Christine Counsell, professora da Faculdade de Educação da Universidade de Cambridge (UK), e sua explicação está disponível para associados da Historical Association em www.history. org.uk/resources/secondary_resource_2444.html; Acesso em: 31 jan. 2012.

${ }^{19}$ Sobre o uso de biografias no ensino de história, ver também: ALBERTI, Verena. Biografias dos avós: uma experiência de pesquisa no ensino médio. Trabalho apresentado no Simpósio "Ensino de história: saberes e práticas curriculares", coordenado por Ana Maria 
Monteiro (UFRJ), Arlette Gasparello (UFF) e Carmen Gabriel (UFRJ), no XII Encontro Regional de História "Usos do passado", organizado pela Associação Nacional de História (Anpuh) - Rio de Janeiro. Niterói, UFF, 14-18 ago. 2006. Disponível em: cpdoc.fgv.br/ producao_intelectual/arq/1564.pdf.

${ }^{20}$ Ver, entre outros: RAMOS, André Raimundo Ferreira. Escravidão indígena: entre o mito e novas perspectivas de debates. Revista de Estudos e Pesquisas, Brasília: Ministério da Justiça, Fundação Nacional do Índio, Coordenação Geral de Estudos e Pesquisas, v.I, n.1, 2004. Disponível em: www.funai.gov.br/projetos/Plano_editorial/Pdf/REP1-1/8-A\%20 escravid\%E3o\%20do\%20ind\%EDgena\%20-\%20entre\%20o\%20mito\%20e\%20novas\%20 perspectivas\%20de\%20debate\%20-\%20Andr\%E9\%20Ramos.pdf; Acesso em: 2 jul. 2011.

${ }^{21} \mathrm{Na}$ seleção do material desta unidade, será de grande valia, ao lado de outros estudos, a compilação de CUNHA, Manuela Carneiro da. Os direitos do índio: ensaios e documentos. São Paulo: Brasiliense, 1987.

${ }^{22}$ Ferramenta semelhante pode ser encontrada em: www.nationalarchives.gov.uk/cabinetpapers/alevelstudies/what-is-writing-frame.htm; Acesso em: 31 jan. 2012.

${ }^{23}$ Ver exemplo interessante para o caso da campanha pelo voto feminino na Inglaterra em: www.nationalarchives.gov.uk/education/britain1906to1918/g3/gallery3.htm; Acesso em: 31 jan. 2012.

${ }^{24}$ A esse respeito, ver MARTIN, Dave. What do you think? Using online forums to improve students' historical knowledge and understanding. Simulating History, Historical Association, Dec. 2008, p.31-38; e SNAPE, Dominic; ALLEN, Katy. Challenging not balancing: developing Year 7's grasp of historical argument through online discussion and a virtual book. Teaching History, v.133, cit., p.45-51. Disponível para membros da Historical Association em: www.history.org.uk/resources/secondary_resource_1976_12.html; Acesso em: 31 jan. 2012.

${ }^{25}$ Discuto questões sensíveis e controversas também nos textos citados na nota 14 .

${ }^{26}$ Ver, a respeito: www.asia.si.edu/EncompassingtheGlobe/Africa.htm; Acesso em 31 jan. 2012.

Artigo recebido em 20 de janeiro de 2012. Aprovado em 26 de março de 2012. 